\title{
Yüksek riskli prostat kanserinde robotik ve açık radikal prostatektominin erken-dönem erektil fonksiyon sonuçlarının karșılaștırılması
}

\section{Comparison of short-term erectile function results of robotic and open radical prostatectomy in high-risk prostate cancer}

\author{
Fuat Kızılay®, Serdar Kalemciఠ, Barıș Altay®
}

\section{öz}

\begin{abstract}
AMAÇ: Robot-yardımlı (RYRP) ve retropubik (RRP) radikal prostatektominin fonksiyonel sonuçlarını karşılaştıran çok sayıda çalışma olmasına rağmen, yüksek-riskli hasta grubu gibi seçilmiş bir hasta grubunda karşılaştıran çalışma sayısı kısıtlıdır. Bu çalışmada, yüksek-riskli prostat kanserli (PK) hastalarda bu iki yöntemin ereksiyon sonuçlarının karşılaştırılması amaçlandı.

GEREÇ ve YÖNTEM: Yüksek-riskli PK nedeniyle RRP uygulanan 84 hasta ve RYRP uygulanan 60 hasta çalışmaya dahil edildi. Hastaların demografik verileri, perioperatif veriler, hastaya ve hastalığa özgü faktörler, preoperatif ve postoperatif 3. ay Uluslararası Erektil Fonksiyon İndeksi (IIEF) skorları, hasta dosyalarından retrospektif olarak kaydedildi. Çalışmanın birincil amacı, iki yöntem arasında erektil fonksiyondaki değişimin karşılaştırılmasıydı; ikincil amacı ise iki yöntem arasındaki perioperatif verilerin ve onkolojik sonuçların karşılaştırılmasıydı. İstatistiksel anlamlılık için 0,05'den küçük p değerleri kabul edildi

BULGULAR: İki grubun demografik ve histopatolojik verileri benzerdi. İki grupta da postoperatif 3. ayda bakılan IIEF skorunda belirgin azalma mevcuttu (birinci grupta $-10,42 \pm 2,72$ ve ikinci grupta $-9,82 \pm 1,86$ puan, $\mathrm{p}=0,330$ ). Bununla uyumlu şekilde her iki grupta da orta ve ileri düzeyde erektil disfonksiyonu olan hasta oranında artış mevcuttu ancak bu oranlar arasında anlamlı bir farklılık yoktu. Her iki grupta da hastaların yaklaşık yarısında potens korunmuştu. Ayrıca, operasyon süresi RRP lehine bulunurken $(p=0,024)$, postoperatif kateterizasyon süresi ve tahmini kan kaybı, RYRP lehine bulundu (sırasıyla, $\mathrm{p}=0,019$ ve $\mathrm{p}=0,036)$.
\end{abstract}

SONUC:: Radikal prostatektomi, yüksek-riskli PK hastalarında düşük komplikasyon oranları ve erken dönem kabul edilebilir potens oranlarıyla güvenle uygulanabilir. Açık ve robotik teknik arasında yüksek-riskli PK hastalarında erken dönem erektil fonksiyonların korunmasında önemli bir fark saptanmamıştır.

Anahtar Kelimeler: robot-yardımlı radikal prostatektomi, retropubik radikal prostatektomi, erektil disfonksiyon, fonksiyonel sonuçlar

\section{ABSTRACT}

OBJECTIVE: The number of studies comparing the functional results of robot-assisted (RARP) and retropubic (RRP) radical prostatectomy, in a high-risk group of patients, is limited. In this study, we compared the erectile function results of these two methods in patients with high-risk prostate cancer (PCa).

MATERIAL and METHODS: Eighty-four patients who underwent RRP and 60 patients who underwent RARP for high-risk PCa were included in this study. Demographic data, perioperative data, patient and disease specific factors, preoperative and postoperative 3rd month International Index of Erectile Function (IIEF) scores were recorded retrospectively from hospital registration system. The primary aim of the study was to compare the change in erectile function between two methods; the secondary aim was to compare the perioperative data and oncologic results between the two methods. $P$ values less than 0.05 were accepted for statistical significance.

RESULTS: Demographic and pathological data of the two groups were similar. There was a significant decrease in the IIEF score in the postoperative 3rd month in both groups $(-10.42 \pm 2.72$ in the first group and-9.82 \pm 1.86 in the second group, $\mathrm{p}=0.330$ ). Consistent with this finding, there was an increase in the number of patients with intermediate and advanced erectile dysfunction in both groups, but there was no significant difference between these groups. In both groups, the potency was preserved in approximately half of the patients. In addition, the mean operation time was found in favor of RRP $(p=0.024)$, while mean postoperative catheterization time and estimated blood loss were found in favor of RARP ( $\mathrm{p}=0.019$ and $\mathrm{p}=0.036$, respectively).

CONCLUSION: Radical prostatectomy can be performed safely in patients with high-risk PCa with low complication rates and acceptable early potency rates. There was no significant difference between the open and the robotic technique for the preservation of short-term erectile function.

Keywords: robot-assisted radical prostatectomy, retropubic radical prostatectomy, erectile dysfunction, functional results

\section{Giriș}

Ege Üniversitesi Tıp Fakültesi, Üroloji Anabilim Dalı, İzmir

Yazışma Adresi/ Correspondence:

Uzm. Dr. Fuat Kızılay

Ege Üniversitesi Hastanesi Üroloji Anabilim Dalı Bornova/İzmir, Türkiye

Tel. $\quad+902323902500$

E-mail: fuatkizilay@gmail.com

Geliš/ Received: $\quad 10.06 .2019$

Kabul/ Accepted: 18.07.2019
Prostat kanseri (PK), erkeklerde akciğer kanserinden sonra en sık ölüme neden olan ikinci kanser olup, 2018 yılında dünya çapında yaklaşık 1,3 milyon erkeğe PK tanısı konmuş ve hastalığa bağlı 359,000 ölüm meydana gelmiştir. [1] Prostat-spesifik antijenin (PSA) yaygın kullanılmasıyla 
daha fazla sayıda hasta erken dönemde PK tanısı almakta ve bu hastalarda erken evrede küratif tedavi uygulanarak genel ve hastalığa bağlı sağkalım oranlarını azaltmak mümkün olmaktadır. ${ }^{[2]}$ Yaşam beklentisi 10 yılın üzerinde olan klinik lokalize PK için radikal prostatektomi (RP), küratif amaçla yaygın uygulanan bir cerrahi tedavi yöntemdir. ${ }^{\left[{ }^{[3]}\right.}$ $\mathrm{Bu}$ yöntem, geleneksel olarak açık retropubik RP (RRP) olarak yapılmaktadır, ancak son yıllarda laparoskopik ve robot-yardımlı RP (RYRP) olarak da uygulanmaktadır. RP, hangi yöntemle uygulanırsa uygulansın iki majör komplikasyon olan erektil disfonsiyon (ED) ve inkontinansin yanında, perioperatif komplikasyonlar ve üretral striktürler gibi nadir görülen komplikasyonlar da meydana gelebilmektedir. ${ }^{[4]}$

RP'den sonra meydana gelen ED, uzun-dönem etkileri ile bazı otörler tarafından tedavi sonrası yaşam kalitesini etkileyen en önemli faktör olarak görülmektedir. ${ }^{[5]}$ Türkiye'de 40 yaşın üzerindeki her 3 erkekten birisinde ED görüldüğü bilinmektedir. ${ }^{[6]}$ İskandinav PK grubu çalışmasında cerrahiden 12 yıl sonra ED'nin, yaşam kalitesinde hafif-orta düzeyli bir etkilenme için en önemli risk faktörü olduğu ortaya konmuştur. ${ }^{[7]} \mathrm{RP}$ sonrasında onkolojik sonuçlar yanında fonksiyonel sonuçlar da dikkate alınması gereken bir konudur. Bugün için Birleşik Devletler'de uygulanan RP'lerin yaklaşık \%80'inden fazlasında tercih edilen robotik teknik, önemli tartışmalara konu olmaktadır. Bazıları bu yeni yöntemin tek farkının maliyeti olduğunu öne sürmekte ve fonksiyonel sonuçlar açısından fayda sağlamadığını iddia etmektedir. Yakın zamandaki bir randomize-kontrollü çalışmada, açık ve robotik tekniğin kısa dönemde benzer sonuçlar sağladığı gösterilmiştir. ${ }^{\left[{ }^{[]}\right.}$Geniş hasta grubuna sahip prospektif bir çalışmada RYRP'nin perioperatif sonuçlarda bazı iyileşmelerle birlikte güvenli bir yöntem olduğu vurgulanmıştır. ${ }^{[9]}$ Ancak bu çalışmaların bazılarının heterojen ve kısıtlı hasta grubu içermeleri ve bazılarında ise operasyonların farklı cerrahlar tarafindan uygulanması nedeniyle bu konuda kesin bir önerme yapmak mümkün olamamaktadır.
Robotik tekniğin sağladığı üç boyutlu ve büyütülmüş görüntü, geniş açılı enstrümanlar, RP'de erektil fonksiyondan bizzat sorumlu olan kavernöz sinirlerin korunmasında büyük fayda sağlamaktadır. Ancak, ne var ki, ekstrakapsüler hastalık riskinin fazla olduğu cT2 c veya cT3 veya biyopsi ISUP derecesi $>3$ olan hastalarda sinir-koruyucu cerrahi rölatif kontrendikedir. Hastada rezidü tümör bırakma şüphesi varsa, nörovasküler demet (NVD) mutlaka rezeke edilmelidir. Yüksek-riskli PK hastalarında robotik tekniğin açık tekniğe göre avantaj sağlayıp sağlamadığı, merak edilen bir konudur. Çalışmamızda, kliniğimizde yüksek-riskli PK nedeniyle açık ve robotik teknikle RP uygulanan hastaların ereksiyon ve perioperatif sonuçlarını karşılaşıırdık.

\section{GEREÇ VE YÖNTEM}

\section{Hasta seçimi ve veri toplanması}

Mart 2011 ve Mart 2019 arasında RRP uygulanan toplam 748 hasta ve RYRP uygulanan 522 hasta çalışma için değerlendirildi. Avrupa Üroloji Birliği (EAU) risk sınıflamasına göre ${ }^{[10]}$ düşük ve orta risk grubuna giren, RRP grubundan 662 ve RYRP grubundan 448 hasta, dışlandı. Dahil edilme kriterlerine uymayan her iki gruptan toplam 16 hasta daha çalışma dışında bırakıldıktan sonra geriye kalan toplam 144 hasta çalışmaya dahil edildi. Bunların 84'ü RRP grubunda, 60'ı ise RYRP grubundaydı. Çalışmanın akış şeması, Şekil 1'de özetlenmiştir.

PSA $>20 \mathrm{ng} / \mathrm{mL}$ olması ve/veya Gleason skoru $>7$ olması ve/ veya cT2 c hastalık olması, preoperatif Uluslararası Erektil Fonksiyon İndeksinin (IIEF-6) $\geq 17$ olması, dahil edilme kriterleriydi. Preoperatif orta-şiddetli düzeyde ED olması (IIEF-6<17), neoadjuvan tedavi alması (androjen ablasyon tedavisi ve radyoterapi), PSA nüksü olan hastalar ve daha önce prostatla ilgili veya başka bir nedenle pelvik cerrahi geçirmiş olmak, dışlanma kriterlerini oluşturmaktaydı.

Hastaların demografik verileri, perioperatif veriler, hastaya ve hastalığa özgü faktörler, preoperatif ve postoperatif 3. ay IIEF skorları, hasta dosyalarından retrospektif olarak kaydedildi.

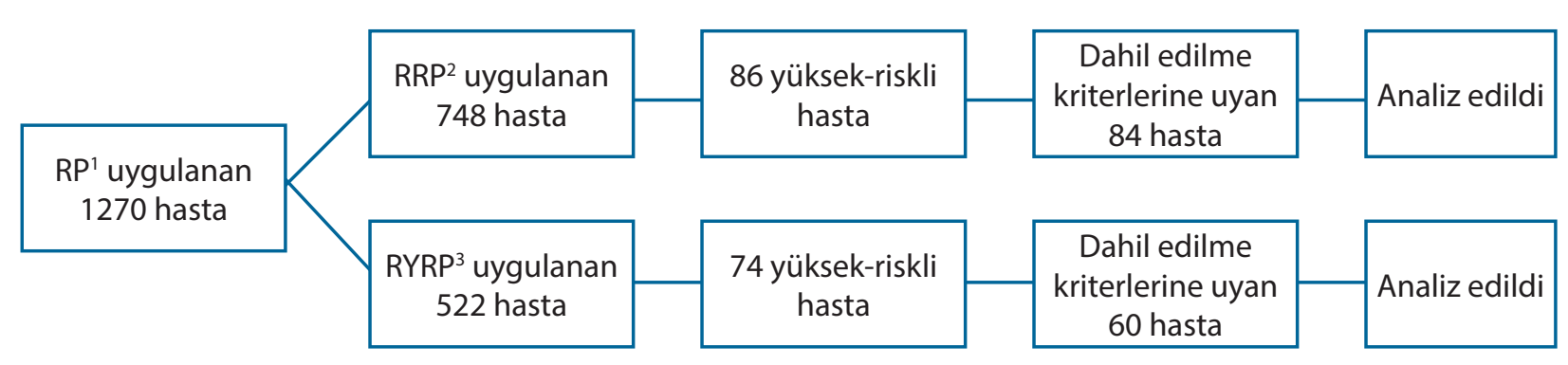

Şekil 1. Çalışma akış şeması.

${ }^{1}$ RP: Radikal Prostatektomi, ${ }^{2}$ RRP: Retropubik Radikal Prostatektomi, ${ }^{3}$ RYRP: Robot-Yardımlı Radikal Prostatektomi 


\section{Postoperatif hasta takibi}

Tüm hastalara postoperatif dönemde taburculuk sonrası

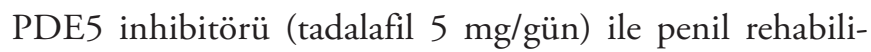
tasyon tedavisi ve foley sonda alınmasını takiben Kegel egzersizleri başlandı. Postoperatif 2. ayda PSA kontrolü yapılarak, PSA'nın ölçülemeyecek düzeyde olması konfirme edildi. Bu sırada hastaların RP histopatolojileri değerlendirildi ve postoperatif Gleason skoru, patolojik evre ve cerrahi sınır durumu kaydedildi.

\section{Değerlendirme kriterleri ve sonlanım ölçütleri}

Hastaların düşük, orta ve yüksek riskli olarak sınıflandırılması için D'Amico sınıflandırma sistemine dayanan EAU risk grubu sınıflandırılma sistemi kullanıldı. Buna göre PSA $>20 \mathrm{ng} / \mathrm{mL}$ olması veya Gleason skoru $>7$ olması veya cT2 c hastalık olması, yüksek riskli PK olarak kabul edildi. Erektil fonksiyon durumu, IIEF-6 sorgulama formuna göre sınıflandırıldı: 26-30 normal ereksiyon, 17-25 hafif $\mathrm{ED}, 11-16$ orta düzeyde $\mathrm{ED}$ ve 1-10 şiddetli düzeyde $\mathrm{ED}$ olarak sınıflandırıldı. IIEF-6 formu, hastalara 3., 6. ve 12. aylarda dolduruldu, ancak 3. aydaki skor, bu çalışmanın erken dönem değerlendirme ölçütüydü.

İki yöntem arasında erken dönemdeki erektil fonksiyondaki değişimin ortaya konulması, çalışmanın birincil sonlanım noktasıydı. İki grup arasındaki perioperatif verilerin karşılaştırılması ise, çalışmanın ikincil sonlanım noktasıydı.

\section{İstatistiksel analiz}

Numerik verilerin karşılaştırılması için Student t-test veya Mann-Whitney U-test kullanıldı. Nominal verinin karşılaştırılması için ise ki-kare testi kullanıldı. İstatistiksel analiz için SPSS versiyon 22,0 (SPSS, Inc., Chicago, IL, USA) kullanıldı. İstatistiksel anlamlılık için 0,05'den küçük $\mathrm{p}$ değerleri kabul edildi.

\section{BULGULAR}

Çalışmaya dahil edilen toplam 144 hastanın klinik ve demografik verileri ve görülen perioperatif komplikasyonlar, Tablo 1'de özetlenmiştir. İki grupta, demografik veriler, PSA, biyopsi ve prostatektomi Gleason skoru, klinik ve patolojik evre benzerdi $(p>0,05)$. Ancak, her iki grupta $\mathrm{da}$, prostatektomi Gleason skorunda biyopsidekine göre skor yükselmesi ve patolojik evrede klinik evreye göre evre yükselmesi görüldü (birinci grupta Gleason 8, 9 ve 10'da sirasıyla \%2,3, \%2,3 ve \%2,4; ikinci grupta Gleason 9 ve 10 'da $\% 5$ oranında yükselme gözlendi. Ayrıca birinci grupta $\mathrm{pT} 3 \mathrm{~b}$ ve $\mathrm{pT} 4$ evrelerinde sırasiyla, $\% 8,3$ ve $\% 3,5$ oranında; ikinci grupta ise sırasıyla $\% 11,7$ ve $\% 1,7$ oranında evre yükselmesi mevcuttu). Altmış hastada cerrahi sınır pozitifliği mevcuttu $(\% 41,7)$. Operasyon süresi RRP lehine bulunurken $(p=0,024)$, postoperatif kateterizasyon süresi ve tahmini kan kaybı, RYRP lehine bulundu (sırasıla, $\mathrm{p}=0,019$ ve $\mathrm{p}=0,036$ ). Perioperatif komplikasyonlar açısından iki grup arasında anlamlı bir farlılık izlenmedi $(\mathrm{p}=0,127)$.

İki grubun preoperatif ortalama IIEF skorları ve hafif-orta-ileri derecede ED'si olan ve potent hasta oranları arasında anlamlı bir farklılık yoktu ( $>0,05)$. Her iki grupta da postoperatif 3. ayda bakılan IIEF skorunda belirgin azalma mevcuttu (birinci grupta-10,42 $\pm 2,72$ puan ve ikinci grupta-9,82 $\pm 1,86$ puan, $p=0,330$ ). Bununla uyumlu şekilde her iki grupta da orta ve ileri düzeyde ED'si olan hasta oranında artış mevcuttu ancak bu oranlar arasında anlamlı bir farklılık yoktu ( $p>0,05)$. İki gruptaki preoperatif ve postoperatif IIEF skorlarının ve hastaların potens durumlarının karşılaştırılması, Tablo 2'de özetlenmiştir.

\section{TARTIȘMA}

Çalışmamızda, yüksek-riskli PK tedavisinde gerek açık, gerekse robotik tekniğin benzer komplikasyon oranlarıyla ve kısa dönem kabul edilebilir erektil fonksiyon sonuçlarıyla uygulanabileceğini ortaya koyduk. Ficarra ve ark.'nın çalışmasında, RYRP uygulanan hastaların 12 ay sonundaki erektil fonksiyonu geri kazanan hasta oranı, RRP uygulanan hastaların yaklaşık iki katıydı (\%81 vs \%49), ancak her iki grupta yüksek riskli PK özelliklerine sahip hasta oranı \%40'dan fazla değildi. ${ }^{[11]}$ Bu çalışma aynı zamanda iki yöntemin fonksiyonel sonuçlarını karşılaştıran ilk prospektif çalışma olma özelliğine sahipti. Diğer bir eşleşmeli-karşılaştırma çalışmasında, hasta grubunun büyük kısmı düşük ve orta riskli hasta grubundan oluşmaktaydı, büyük kısmında sinir koruyucu cerrahi gerçekleştirilmişti ve 1 yıllık takipte iki yöntem arasında fonksiyonel sonuçlar arasında bir fark gözlenmedi. ${ }^{[12]}$ Ancak sonuçların valide edilmemiş sorgulama formlarıyla değerlendirilmiş olması, bu çalışmanın önemli bir eksikliğiydi. Çimen ve ark.'nın çalışmasında, yukarıda bahsedilen çalışmaya benzer şekilde kısa ve uzun dönem takiplerde açı ve robotik cerrahi teknik arasında fark saptanmamıştır. ${ }^{[13]}$ Ancak bu çalışmada da PK hastalarının büyük çoğunluğu, düşük ve orta risk grubundaydı. Ayrıca, bu çalışmada robotik gruptaki hastaların öğrenme eğrisindeki dönemde opere edilmesi, iki grup arasındaki benzer sonuçları açıklayan bir faktör olabilir. Hastalarımızdaki pozitif cerrahi sınır oranı, Çimen ve ark.'nın çalışmasındaki orandan daha yüksekti (\%41,7 vs \%26,5). Bunun nedeninin, hasta grubumuzun yüksek riskli hastalardan oluşması olduğunu düşünmekteyiz. 
Tablo 1. Hastaların klinik ve demografik verilerinin ve perioperatif komplikasyonlarının

\begin{tabular}{|c|c|c|c|}
\hline Değişkenler & Grup $1^{a}$ & Grup $I^{b}$ & $P$ değeri \\
\hline Hasta sayısı & 84 & 60 & \\
\hline Yaş & $61,6 \pm 5,8$ & $57,4 \pm 4,9$ & 0,311 \\
\hline \multicolumn{4}{|l|}{ Kronik hastalıklar } \\
\hline Diyabetes mellitus & $8(\% 9,5)$ & $6(\% 10)$ & \multirow{4}{*}{0,428} \\
\hline Hipertansiyon & $12(\% 14,3)$ & $10(\% 16,7)$ & \\
\hline Hiperlipidemi & $13(\% 15,5)$ & $11(\% 18,3)$ & \\
\hline Koroner arter hastalığı & $10(\% 11,9)$ & $8(\% 13,3)$ & \\
\hline Vücut kitle indeksi $\left(\mathrm{kg} / \mathrm{m}^{2}\right)$ & $25,1 \pm 3,9$ & $24,4 \pm 4,6$ & 0,644 \\
\hline PSAc (ng/mL) & $18,2 \pm 3,9$ & $21,6 \pm 4,0$ & 0,209 \\
\hline \multicolumn{4}{|l|}{ Biyopsi Gleason skoru } \\
\hline 7 & $28(\% 33,3)$ & $19(\% 31,7)$ & \multirow{4}{*}{0,069} \\
\hline 8 & $15(\% 17,9)$ & $11(\% 18,3)$ & \\
\hline 9 & $25(\% 29,8)$ & $22(\% 36,7)$ & \\
\hline 10 & $16(\% 19,0)$ & $8(\% 13,3)$ & \\
\hline \multicolumn{4}{|l|}{ Prostatektomi Gleason skoru } \\
\hline 7 & $22(\% 26,2)$ & $16(\% 26,7)$ & \multirow{4}{*}{0,192} \\
\hline 8 & $17(\% 20,2)$ & $8(\% 13,3)$ & \\
\hline 9 & $27(\% 32,1)$ & $25(\% 41,7)$ & \\
\hline 10 & $18(\% 21,4)$ & $11(\% 18,3)$ & \\
\hline \multicolumn{4}{|l|}{ Klinik evre } \\
\hline cT2 c & $28(\% 33,3)$ & $19(\% 31,7)$ & \multirow{4}{*}{0,841} \\
\hline сТЗа & $22(\% 26,2)$ & $20(\% 33,3)$ & \\
\hline cT3b & $20(\% 23,8)$ & $12(\% 20,0)$ & \\
\hline cT4 & $14(\% 16,7)$ & $9(\% 15,0)$ & \\
\hline \multicolumn{4}{|l|}{ Patolojik evre } \\
\hline pT2 c & $23(\% 27,4)$ & $18(\% 30)$ & \multirow{4}{*}{0,594} \\
\hline рТ3а & $17(\% 20,2)$ & $13(\% 21,7)$ & \\
\hline рT3b & $27(\% 32,1)$ & $19(\% 31,7)$ & \\
\hline pT4 & $17(\% 20,2)$ & $10(\% 16,7)$ & \\
\hline \multicolumn{4}{|l|}{ Cerrahi sınır durumu } \\
\hline Pozitif & $34(\% 40,5)$ & $26(\% 43,3)$ & \multirow[t]{2}{*}{0,710} \\
\hline Negatif & $50(\% 59,5)$ & $34(\% 56,7)$ & \\
\hline Operasyon süresi (dk) & $88,4 \pm 10,2$ & $158,9 \pm 32,4$ & 0,024 \\
\hline $\begin{array}{l}\text { Postoperatif Foley kateterizasyon } \\
\text { süresi (gün) }\end{array}$ & $13,9 \pm 3,1$ & $7,2 \pm 1,8$ & 0,019 \\
\hline Tahmini kan kaybı (ml) & $344,1 \pm 40,3$ & $102,8 \pm 18,4$ & 0,036 \\
\hline \multicolumn{4}{|l|}{ Perioperatif komplikasyonlar } \\
\hline Rektal yaralanma & $8(\% 9,5)$ & $5(\% 8,3)$ & \multirow{4}{*}{0,127} \\
\hline Paralitik ileus & $1(\% 1,2)$ & $4(\% 6,7)$ & \\
\hline İnsizyonel herni & $8(\% 9,5)$ & - & \\
\hline Kardiyovasküler komplikasyonlar & $9(\% 10,7)$ & $9(\% 15,0)$ & \\
\hline
\end{tabular}

aRetropubik radikal prostatektomi uygulanan grup

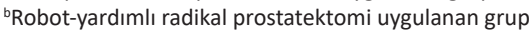

'Prostata-spesifik antijen

Tablo 2. Hastaların Uluslararası Erektil Fonksiyon İndeksindeki değişimlerin karşılaştırılması

\begin{tabular}{|c|c|c|c|}
\hline Değişkenler & Grup $l^{a}$ & Grup $I^{b}$ & $P$ değeri \\
\hline Hasta sayısı & 84 & 60 & \\
\hline Preoperatif IIEF-6 skoru & $22,38 \pm 3,82$ & $23,19 \pm 4,11$ & 0,424 \\
\hline \multicolumn{4}{|l|}{ Preoperatif erektil fonksiyon durumu } \\
\hline Potent hasta sayısı & $32(\% 38,1)$ & $23(\% 38,3)$ & \multirow{4}{*}{0,672} \\
\hline Hafif düzeyde $E D^{d}$ olan hasta sayısı & $21(\% 25,0)$ & $16(\% 26,7)$ & \\
\hline Orta düzeyde ED olan hasta sayısı & $18(\% 21,4)$ & $12(\% 20,0)$ & \\
\hline İleri düzeyde ED olan hasta sayısı & $13(\% 15,5)$ & $9(\% 15,0)$ & \\
\hline Postoperatif IIEF-6 skoru & $12,89 \pm 2,34$ & $13,41 \pm 3,86$ & 0,812 \\
\hline \multicolumn{4}{|l|}{ Postoperatif erektil fonksiyon durumu } \\
\hline Potent hasta sayısı & $17(\% 20,2)$ & $11(\% 18,3)$ & \multirow{4}{*}{0,589} \\
\hline Hafif düzeyde $E D^{d}$ olan hasta sayısı & $14(\% 16,7)$ & $9(\% 15,0)$ & \\
\hline Orta düzeyde ED olan hasta sayısı & $28(\% 33,3)$ & $18(\% 30,0)$ & \\
\hline İleri düzeyde ED olan hasta sayısı & $25(\% 29,8)$ & $22(\% 36,7)$ & \\
\hline IIEF-6 skorundaki değişim & $-10,42 \pm 2,72$ & $-9,82 \pm 1,86$ & 0,330 \\
\hline
\end{tabular}

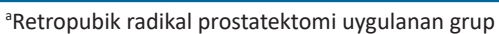

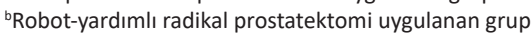

'Uluslararası Erektil Fonksiyon İndeksi

dErektil disfonksiyon 
Geniş serili prospektif non-randomize bir çalışmada D'Amico düşük ve orta risk grubundaki hastalarda RYRP ile erektil fonksiyondaki düzelmenin RRP'ye göre daha fazla olduğu ancak, yüksek-riskli hastalarda 24. aydaki sonuçların açık cerrahiyi ön plana çıkardığı yönündeydi. ${ }^{[14]}$ Bu çalışma, erektil fonksiyonları D’Amico risk gruplarına göre ve cerrahların nörovasküler demet (NVD) koruma durumlarına göre sınıflandırması ile önceki çalışmalardan ayrılmaktaydı. RYRP'nin özellikle rekonstrüktif operasyonlarda sağladığı avantajlar bazen paradoksik olarak istenmeyen sonuçlar da doğurabilir. RYRP ile sağlanan daha iyi görüntü, cerrahların cerrahi planları daha iyi tanımasıyla prostat daha yakın bir mesafede diseksiyon yapmalarına olanak sağlayabilir. Bu durum, zaman zaman prostat kapsülünde istenmeyen hasarlara yol açabilir ve bunun sonucunda erektil fonksiyon olumsuz etkilenebilir. Açı yöntemde ise planların iyi tanınamaması sonucunda prostata daha uzak mesafeden diseksiyon muhtemeldir. Çalışmamızda sinir-koruma bilgisi mevcut değildi ancak, yüksek-riskli hastalarda onkolojik prensiplerden ödün vermemek için NVD’nin de prostatla birlikte alınması konusunda daha rahat karar verildiğini düşünmekteyiz.

Açık ve robotik RP tekniklerinin fonksiyonel sonuçlarının karşılaştırıldığı prospektif, kontrollü, non-randomize diğer bir çalışmada 12 aylık erektil fonksiyonların RYRP lehine olduğu gösterilmişse de, aradaki mutlak fark yalnızca \%4,3'dü. [15] Her ne kadar yüksek risk özellikleri gösteren PK'de NVD'yi korumak rölatif kontrendike olarak kabul edilse de, 584 yüksek riskli PK hastanın retrospektif olarak analiz edildiği bir çalışmada, hastaların yalnızca \%12'sinde bilateral ve \%16'sında unilateral NVD rezeksiyonu yapılmıştı ve NVD korunan hastaların yalnızca \%24'ünde pozitif cerrahi sinır mevcuttu ve 2 yil sonunda hastaların \%47'si preoperatif erektil fonksiyonlarını geri kazanmıştı. ${ }^{[16]} \mathrm{Bu}$ çalışma, yüksek-riskli hastalarda dahi NVD rezeksiyonunun nadiren gerektiğini ortaya koymuştur. Ward ve ark.'nın çalışmasında cT3 evresindeki 841 hastaya RP uygulanmıştı ve hastaların \%74'ünde bilateral NVD rezeksiyonu yapılmıştı ve preoperatif potent hastaların dörtte birinde postoperatif erektil fonksiyon restorasyonu sağlanmıştı. ${ }^{[17]}$ Diğer bir seride, 123 yüksek-riskli hastaya RYRP uygulanmıştı ve hastaların yaklaşı üçte birinde NVD korunmuştu ve hastaların \%58'inde potens bildirilmişti. ${ }^{[18]}$ Abdollah ve ark., pT3 hastalığı olan veya PSA > 10 olan hastalarda patolojik evre ile PSA ile erektil fonksiyon iyileşmesi arasında bağımsız bir ilişki olduğunu göstermiştir. ${ }^{[19]}$ Daha düşük evreli hastalarda, prostatik kapsüle daha yakın bir diseksiyon hattı kullanılması muhtemeldir, bu da NVD korunmasının ve sonuçlarının iyileştirilmesine katkıda bulunmaktadır.

Öteyandan, literatürde farklı sonuçlar bildiren çalışmalar da mevcuttur. Örneğin, 288 vakayı içeren bir tek-cerrah serisinde bilateral NVD korunma oranı \%9 olmasına rağmen, potens oranının \%60 olduğu bildirilmiştir. ${ }^{\left[{ }^{[0]}\right.}$ Novara ve ark.'nın çalışmasında RYRP uygulanan tüm hastalarda farklı düzeylerde NVD korunmuştu, ancak hastaların ancak üçte biri cerrahi sonrasında potentti. ${ }^{[21]}$ Diğer bir seride 148 yüksek-riskli hastanın yaklaşık üçte birinde bilateral NVD korunmuştu ve hastaların yaklaşık yarısı iki yıl sonunda impotand1. ${ }^{[22]} \mathrm{Bu}$ sonuçlara göre, NVD korunma oranları ile potens oranları arasında net bir korelasyon olmadığ1 görülmektedir. RYRP ile daha iyi fonksiyonel ve onkolojik sonuçlar bildiren çalışmaların çoğu, düşük kanıt düzeyine sahip, prospektif, non-randomize veya retrospektif vaka serilerine dayanmaktadır. ${ }^{[23-25]}$ Bizim çalışmamızda her iki yöntemle de opere edilen hastaların yaklaşık yarısında ereksiyon korunmuştu, ancak literatürdeki çelişkili sonuçlara bakarak hastalarımızdaki NVD korunma oranları hakkında sağlıklı bir yorum yapmak mümkün gözükmemektedir.

Preoperatif iyi bir erektil fonksiyona sahip ve daha az yüksek riskli hastalık özelliklerine sahip genç hastalarda onkolojik prensiplerden ödün vermeden mümkün olduğu sürece NVD korunmasına özen gösterilmelidir. Güncel pratikte, PK tedavisinde onkolojik kontrol yanısıra, iyi bir yaşam kalitesinin sağlanması da oldukça önemlidir. ${ }^{[26]}$ Yukarıdaki çelişkili çalışma sonuçları, RP sonrası erektil fonksiyonu öngören tek faktörün NVD korunması olmadığını konfirme etse de, bugün için cerrahi teknik açısından potensin korunması için modifiye edilebilir en önemli belirleyici, sinir koruyucu cerrahi olarak gözükmektedir. Daha önce geliştirilen bazı nomogramlar cerrahların univeya bilateral NVD koruma kararı vermesinde yardımcı olabilir. ${ }^{[27,28]}$ Ayrıca, intraoperatif frozen çalışma veya preoperatif multiparametrik manyetik rezonans görüntüleme, bu karara yardımcı olabilir. ${ }^{[29,30]}$ Yüksek riskli hastalarda NVD'nin tümör tarafindan invazyonu sık görülen bir durum olmamakla birlikte, bu hastalarda belli bir oranda sinir koruma yapılabilir. Prostatın çevre dokulardan diseksiyonu sırasında birçok farklı plana girilebildiğinden dolayı, sinir koruma, ya hep ya hiç bir fenomen olarak görülmemelidir. Tecrübeli cerrahların pratiğinde sinir koruma için uygun hastalar seçilebilir ve pozitif cerrahi sınır oranlarını arttırmadan, sinir koruyucu RP güvenle uygulanabilir.

Çalışmamızın bazı kısıtlılıkları mevcuttur. Birincisi, hastaların sinir koruma bilgileri mevcut değildir. İkincisi çalışmamız, retrospektif ve gözlemsel bir yapıya sahiptir, ancak literatürde bu konudaki çalışmaların büyük kısmı bu şekildedir. Cerrahın deneyiminin RP sonuçlarını etkileyen önemli bir faktör olduğu gözönüne alınırsa, uygulamalar farklı cerrahlar tarafından gerçekleştirilmişti. Son olarak yalnızca erken dönem (3. ay) potens bilgileri mevcuttur. RP sonrasinda erektil fonksiyon restorasyonunun uzun dönemde gelişebileceği gözönüne alındığında bu verileri uzun dönem için yorumlamak yanlış olacaktır. 


\section{SONUC}

Çalışmamızda yüksek riskli PK hastalarında sinir koruma bilgisi vermeksizin RP'nin düşük komplikasyon oranları ve erken dönemde kabul edilebilir potens oranlarılla güvenle uygulanabileceği sonucuna vardık. Açık ve robotik teknik arasında bu fonksiyonun korunmasında önemli bir fark olmaması, çalışmamız neticesinde vardığımız diğer bir önemli sonuçtur.

\section{Hakem Değerlendirmesi}

Dış bağımsız

Çıkar Çatışması

Yazarlar çıkar ilişkisi olmadığını beyan etmişlerdir.

\section{Finansal Destek}

Herhangi bir mali destek alınmamıştır.

\section{Peer-review}

Externally peer-reviewed.

\section{Conflict of Interest}

No conflict of interest was declared by the authors.

\section{Financial Disclosure}

No financial disclosure was received.

\section{KAYNAKLAR}

1. Bray F, Ferlay J, Soerjomataram I, Siegel RL, Torre LA, Jemal A. Global cancer statistics 2018: GLOBOCAN estimates of incidence and mortality worldwide for 36 cancers in 185 countries. CA Cancer J Clin 2018;68:394-424. [CrossRef]

2. Vickers AJ. Prostate Cancer Screening: Time to Question How to Optimize the Ratio of Benefits and Harms. Ann Intern Med 2017;167:509-10. [CrossRef]

3. Mottet N, Bellmunt J, Bolla M, Briers E, Cumberbatch MG, De Santis $M$, et al. EAU-ESTRO-SIOG Guidelines on Prostate Cancer. Part 1: Screening, Diagnosis, and Local Treatment with Curative Intent. Eur Urol 2017;71:618-29. [CrossRef]

4. Gandaglia G, Bravi CA, Dell'Oglio P, Mazzone E, Fossati N, Scuderi S, et al. The Impact of Implementation of the European Association of Urology Guidelines Panel Recommendations on Reporting and Grading Complications on Perioperative Outcomes after Robot-assisted Radical Prostatectomy. Eur Urol 2018;74:4-7. [CrossRef]

5. Sanda MG, Dunn RL, Michalski J, Sandler HM, Northouse L, Hembroff $L$, et al. Quality of life and satisfaction with outcome among prostatecancer survivors. N Engl J Med 2008;358:1250-61. [CrossRef]

6. Çayan S, Kendirci M, Yaman Ö, Aşçı R, Orhan I, Usta MF, et al. Prevalence of erectile dysfunction in men over 40 years of age in Turkey: Results from the Turkish Society of Andrology Male Sexual Health Study Group. Turk J Urol 2017;43:122-9. [CrossRef]

7. Johansson E, Steineck G, Holmberg L, Johansson JE, Nyberg T, Ruutu $M$, Bill-Axelson A. Long-term quality-of-life outcomes after radical prostatectomy or watchful waiting: the Scandinavian Prostate Cancer Group-4 randomised trial. Lancet Oncol 2011;12:891-9. [CrossRef]

8. Yaxley JW, Coughlin GD, Chambers SK, Occhipinti S, Samaratunga H, Zajdlewicz L, et al. Robot-assisted laparoscopic prostatectomy versus open radical retropubic prostatectomy: early outcomes from a randomised controlled phase 3 study. Lancet 2016;388:1057-66. [CrossRef]

9. Wallerstedt A, Tyritzis SI, Thorsteinsdottir T, Carlsson S, Stranne J, Gustafsson O, et al. Short-term results after robot-assisted laparoscopic radical prostatectomy compared to open radical prostatectomy. Eur Urol 2015;67:660-70. [CrossRef]

10. Cooperberg MR, Pasta DJ, Elkin EP, Litwin MS, Latini DM, Du Chane J, Carroll PR. The University of California, San Francisco Cancer of the Prostate Risk Assessment score: a straightforward and reliable preoperative predictor of disease recurrence after radical prostatectomy. J Urol 2005;173:1938-42. [CrossRef]
11. Ficarra V, Novara G, Fracalanza S, D’Elia C, Secco S, lafrate M, et al. A prospective, non-randomized trial comparing robot-assisted laparoscopic and retropubic radical prostatectomy in one European institution. BJU Int 2009;104:534-9. [CrossRef]

12. Krambeck $A E$, DiMarco DS, Rangel LJ, Bergstralh EJ, Myers RP, Blute ML, Gettman MT. Radical prostatectomy for prostatic adenocarcinoma: a matched comparison of open retropubic and robot-assisted techniques. BJU Int 2009;103:448-53. [CrossRef]

13. Çimen Hi, Direk HC, Halis F, Köse O, Gökçe A, Sağlam HS. Radikal prostatektomi sonrası erektil fonksiyon açısından robotik cerrahi ile açık cerrahinin karşılaştırılması. Androl Bul 2018;20:35-38. [CrossRef]

14. Sooriakumaran P, Pini G, Nyberg T, Derogar M, Carlsson S, Stranne J, et al. Erectile Function and Oncologic Outcomes Following Open Retropubic and Robot-assisted Radical Prostatectomy: Results from the LAParoscopic Prostatectomy Robot Open Trial. Eur Urol 2018;73:618-27. [CrossRef]

15. Haglind E, Carlsson S, Stranne J, Wallerstedt A, Wilderang U, Thorsteinsdottir T, et al. Urinary Incontinence and Erectile Dysfunction After Robotic Versus Open Radical Prostatectomy: A Prospective, Controlled, Nonrandomised Trial. Eur Urol 2015;68:216-25. [CrossRef]

16. Recabal P, Assel M, Musser JE, Caras RJ, Sjoberg DD, Coleman JA, et al. Erectile Function Recovery after Radical Prostatectomy in Men with High Risk Features. J Urol 2016;196:507-13. [CrossRef]

17. Ward JF, Slezak JM, Blute ML, Bergstralh EJ, Zincke H. Radical prostatectomy for clinically advanced (cT3) prostate cancer since the advent of prostate-specific antigen testing:15-year outcome. BJU Int 2005;95:751-6. [CrossRef]

18. Lavery HJ, Nabizada-Pace F, Carlucci JR, Brajtbord JS, Samadi DB. Nervesparing robotic prostatectomy in preoperatively high-risk patients is safe and efficacious. Urol Oncol 2012;30:26-32. [CrossRef]

19. Abdollah F, Sun M, Suardi N, Gallina A, Bianchi M, Tutolo $M$, et al. Prediction of functional outcomes after nerve-sparing radical prostatectomy: results of conditional survival analyses. Eur Urol 2012;62:42-52. [CrossRef]

20. Loeb S, Smith ND, RoehI KA, Catalona WJ. Intermediate-term potency, continence, and survival outcomes of radical prostatectomy for clinically high-risk or locally advanced prostate cancer. Urology 2007;69:1170-5. [CrossRef]

21. Novara G, Ficarra V, D'Elia C, Secco S, De Gobbi A, Cavalleri S, Artibani W. Preoperative criteria to select patients for bilateral nerve-sparing roboticassisted radical prostatectomy. J Sex Med 2010;7:839-45. [CrossRef]

22. Jayram G, Decastro GJ, Large MC, Razmaria A, Zagaja GP, Shalhav AL, Brendler CB. Robotic radical prostatectomy in patients with high-risk disease: a review of short-term outcomes from a high-volume center. J Endourol 2011;25:455-7. [CrossRef]

23. Finkelstein J, Eckersberger E, Sadri H, Taneja SS, Lepor H, Djavan B. Open Versus Laparoscopic Versus Robot-Assisted Laparoscopic Prostatectomy: The European and US Experience. Rev Urol 2010;12:3543. https://www.ncbi.nlm.nih.gov/pmc/articles/PMC2859140/

24. Rassweiler J, Hruza M, Teber D, Su LM. Laparoscopic and robotic assisted radical prostatectomy--critical analysis of the results. Eur Urol 2006;49:612-24. [CrossRef]

25. Descazeaud A, Peyromaure M, Zerbib M. Will robotic surgery become the gold standard for radical prostatectomy? Eur Urol 2007;51:9-11. [CrossRef]

26. Çimen Hi, Sağlam HS. Robotik prostat cerrahisi ve cinsel fonksiyon. Androl Bull 2016;18:79-82. https://www.journalagent.com/androloji/ pdfs/AND_18_65_79_82.pdf

27. Graefen M, Haese A, Pichlmeier U, Hammerer PG, Noldus J, Butz K, et al. A validated strategy for side specific prediction of organ confined prostate cancer: a tool to select for nerve sparing radical prostatectomy. J Urol 2001;165:857-63. [CrossRef]

28. Zorn KC, Gofrit ON, Steinberg GP, Taxy JB, Zagaja GP, Shalhav AL. Planned nerve preservation to reduce positive surgical margins during robot-assisted laparoscopic radical prostatectomy. J Endourol 2008;22:1303-9. [CrossRef]

29. Beyer B, Schlomm T, Tennstedt P, Boehm K, Adam M, Schiffmann J, et al. A feasible and time-efficient adaptation of NeuroSAFE for da Vinci robot-assisted radical prostatectomy. Eur Urol 2014;66:138-44. [CrossRef]

30. Rud E, Baco E, Klotz D, Rennesund K, Svindland A, Berge V, et al. Does preoperative magnetic resonance imaging reduce the rate of positive surgical margins at radical prostatectomy in a randomised clinical trial? Eur Urol 2015;68:487-96. [CrossRef] 